\title{
Estimation of Aerosol-Corrected Surface Solar Irradiance at Local Incidence Angle over Different Physiographic Subdivisions of India and Adjoining Areas Using MODIS and SRTM Data
}

\author{
LIBEESH LUKOSE \\ Department of Geology and Geophysics, Indian Institute of Technology, Kharagpur, West Bengal, India \\ DIBYENDU DUTTA \\ Climate Studies Group, National Remote Sensing Center, Balanagar, Telengana, India
}

(Manuscript received 5 November 2018, in final form 22 November 2019)

\begin{abstract}
Surface solar irradiance is considered as an important component of the surface radiation budget and constitutes one of the essential climate variables. In the present study, clear-sky instantaneous solar irradiance was estimated over 15 physiographic regions of India during January. Dewpoint temperature profiles were extracted from Moderate Resolution Imaging Spectroradiometer (MODIS) instrument onboard the Aqua satellite to calculate actual vapor pressure following Clausius-Clapeyron equation, which was further used in the Zillman parameterization for solar irradiance. The effect of terrain slope and aspect on direct radiation was taken into account by modifying the parameterized incoming shortwave flux by introducing the local incidence angle. A significant positive correlation was found between terrain-corrected MODIS irradiance and measured radiation data but the RMSE was very high $\left(187 \mathrm{~W} \mathrm{~m}^{-2}\right)$. Further, the effect of aerosol extinction was introduced by multiplying the terrain-corrected flux by a transmission factor obtained from satellite-derived aerosol optical depth and Ångström exponent. Due to the inclusion of the aerosol transmittance, the correlation was significantly improved $\left(R^{2}=0.84\right)$ and RMSE was reduced $\left(31 \mathrm{~W} \mathrm{~m}^{-2}\right)$. Further the effect of surface orientation on surface irradiance was evaluated on six hilly subdivisions. A large variation in the flux ( 135 to $161 \mathrm{~W} \mathrm{~m}^{-2}$ ) was noticed among different aspect classes. The variability was highest in the Eastern Himalayas subdivision $\left(>250 \mathrm{~W} \mathrm{~m}^{-2}\right)$ and was a minimum in the Eastern Hills subdivision $\left(<28 \mathrm{~W} \mathrm{~m}^{-2}\right)$. In absence of ground radiation data in hills, Modern-Era Retrospective Analysis for Research and Applications, version 2 (MERRA-2), was used for validation of model output but it performed poorly and got saturated at higher surface irradiance values.
\end{abstract}

\section{Introduction}

Surface solar irradiance is considered as an important component of the surface radiation budget and constitutes one of the essential climate variables by the Global Climate Observing System (GCOS). Accurate estimation of surface solar irradiance is important for an understanding of energy exchange process between the atmosphere and Earth's surface (Jacobson 1999; Oliphant et al. 2003), agricultural applications (Fu and Rich 2002), and establishing solar energy plants (Sukhera and Pasha 1987). However, direct ground measurements of solar irradiance on the surface are rarely available, especially over mountainous and rugged terrain. As

\footnotetext{
Corresponding author: Dibyendu Dutta,ddisro@gmail.com
}

an approximation, several empirical models have been developed (Urraca et al. 2017a) using either astronomical parameters or meteorological variables like diurnal temperature range (Pellicciotti et al. 2011). It is known that on a clear-sky day the solar radiation flux recorded on Earth's surface follows a cosine response with respect to the time of the day but it is significantly modified by the season, orientation, latitude, altitude, precipitable water vapor, aerosols, ozone content, and surface topography (Iqbal 1983; Hofierka and Cebecauer 2008; Coops et al. 2000), particularly in hilly regions. In the absence of a close network of radiation stations, the data from the geostationary satellite are the most extended approach (Sengupta et al. 2015) for its high temporal resolution and moderate ground resolution. But they are constrained by geographic coverage in the polar regions. 
The reanalysis data are one of the most promising approaches in this direction, which assimilates a large number of ground-based weather parameters and satellite data with the objective to provide a long-term, consistent, and accurate database for climate change studies. Most of the global reanalysis product is coarse in spatial resolution $(30-80 \mathrm{~km})$ and do not generally assimilate local orography, cloud, aerosol, or water vapor data, which increases the uncertainty in surface solar irradiance (You et al. 2013; Zhao et al. 2013). Bojanowski et al. (2014) and Urraca et al. (2017b) found that the quality of reanalysis data is poorer than satellite-derived products, especially in the hilly and coastal areas.

High mountains and rugged terrain introduce an additional source of variability in the solar irradiance assessment through terrain shading, sky view reduction, and elevation variability (Ruiz-Arias et al. 2011). At local scales, terrain features are the major forcing factor driving the spatial variability of solar radiation. They cause strong spatial and temporal gradients in the solar irradiance field (Tover et al. 1995; Oliphant et al. 2003; Tovar-Pescador et al. 2006). Tian et al. (2001) have reported that when the solar zenith angle is high the direct solar beam is intercepted by surrounding hills, which can reduce the energy received at the ground level by as much as $20 \%-30 \%$. The interaction between surface orientation and sun inclination can result in either a net increase or decrease of the solar flux depending on the relative position of the sun with respect to the surface. The elevation also causes a variation in the optical pathlength resulting in changes the solar radiation. Hence if the terrain effects are not considered then the shortwave flux at the surface can be reduced (or increased) by up to hundreds of watts per square meter (Ruiz-Arias et al. 2011). This change could affect local circulation patterns and temperature regimes of locations that are only meters apart (McVicar et al. 2007; Geiger et al. 2009; Fridley 2009). At spatial scale, the topographic effects are especially important when the horizontal resolution is better than $1 \mathrm{~km}$. Ruiz-Arias et al. (2011) proposed a postprocessing disaggregation method to downscale solar irradiance, modeled by numerical weather prediction (NWP) to assess terrain effects on the solar radiation including surface slope, aspect, shadow casting, and sky-view reduction. A notable increase in the variability of solar radiation is reported in terms of a decrease in the value of minima and an increase in the value of maxima has been reported by Ruiz-Arias et al. (2011). As the slope factor is very sensitive to surface orientation, a small uncertainty in the aspect of a surface oriented eastward or westward will produce a large uncertainty in the incoming flux on the surface depending upon the sun's position.
Besides surface topography atmospheric aerosols, in general, play a significant role in Earth's radiation budget (Steiner et al. 2013) in a number of ways especially through radiative forcing and chemical perturbations. The aerosols affect the climate of Earth both directly (by absorption and scattering) and indirectly (by altering the cloud properties), which depends upon their optical and chemical properties. Higher aerosol loading causes a substantial decrease in sunlight reaching to the surface. Aerosol optical depth, a measure of extinction of solar irradiance due to columnar aerosols is considered to be a good proximal indicator of the suspended particulate matters present in the atmospheric column. Satellite-derived columnar aerosol optical depth is a cost-effective way to measure spatiotemporal variability of aerosol optical properties and its effect on surface-reaching solar irradiance.

The present research is aimed at generating aerosol- and orography-corrected high-resolution $(\sim 1 \mathrm{~km})$ shortwave flux from Moderate Resolution Imaging Spectroradiometer (MODIS) data over different physiographic subdivisions (PSDs) of India and adjoining areas. The study is based upon the parameterization scheme of Zillman and Clausius-Clapeyron equation where column integrated dewpoint temperature from satellite data was used for measurement of actual vapor pressure. To account for the effect of surface topography in the mountainous and rugged-terrain surface irradiance has been calculated at local incidence angle using Shuttle Radar Topography Mission (SRTM) digital elevation model (DEM) following the method given by Gates (1980). The aerosol transmission was derived using the modified Yang model, where MODIS aerosol optical depth (AOD) and "Ångström exponent" have been used. The results were validated using ground radiation measurements as well as Modern-Era Retrospective Analysis for Research and Applications, version 2 (MERRA-2) data. This chosen surface-resolution grid $(\sim 1 \mathrm{~km})$ will help to avoid subgrid disaggregation and downscaling and also will be able to filter out the additional uncertainty caused by numerical derivation of the topographic parameters from DEM by compensating over- and underestimation.

\section{Study area}

The study area includes India and adjoining countries, namely, Nepal and Bhutan. The area is bounded by $6.525^{\circ}-37.119^{\circ} \mathrm{N}, 67.994^{\circ}-95.253^{\circ} \mathrm{E}$, covering $3287240 \mathrm{~km}^{2}$. Based upon the tectonic history, stratigraphy, and physiography, the study area has been divided into 6 physiographic divisions and 15 subdivisions (Fig. 1). The subdivisions are as follows: Western 


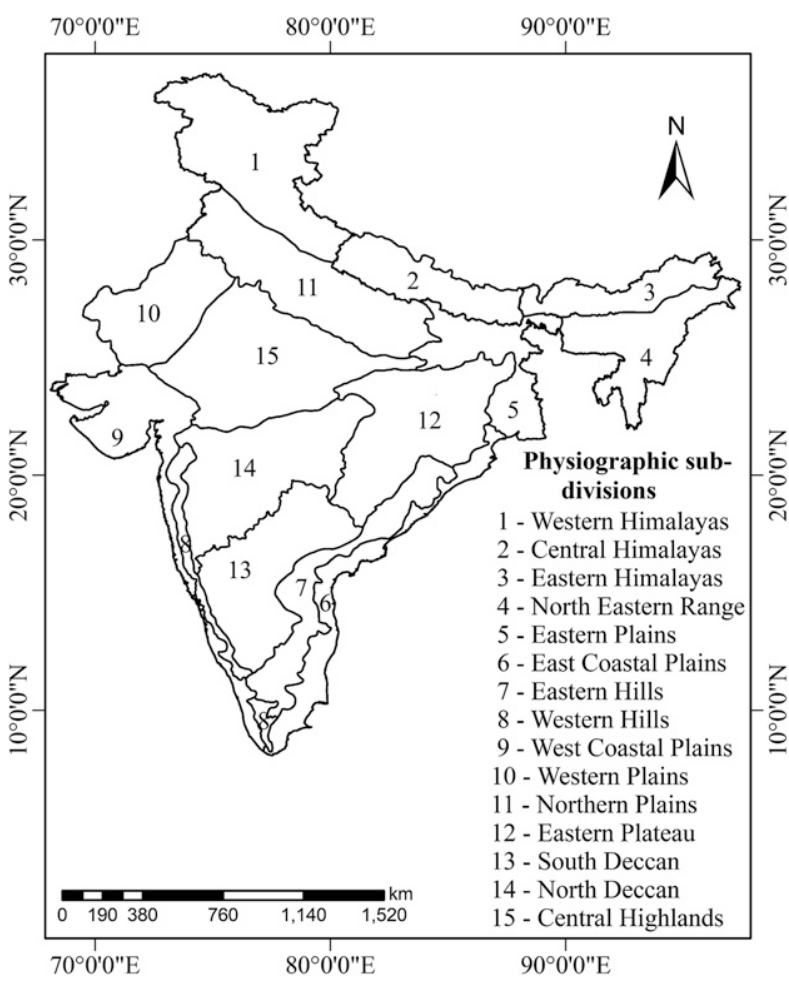

FIG. 1. Physiographic subdivisions of the study area.

Himalayas, Central Himalayas, Eastern Himalayas, North Eastern Range, Western Plain, Northern Plain, Eastern Plain, Eastern Plateau, Central Highlands, North Deccan, South Deccan, Western Hills, Eastern Hills, East Coastal Plain, and West Coastal Plain. The Nepal and Bhutan constitute part of Central and Eastern Himalayas, respectively.

\section{Data used}

\section{a. Aqua MODIS geolocation products}

In the present study, daily Aqua MODIS collection 6 (MYD03) products of January 2008 and 2014 were obtained online (from https://ladsweb.nascom.nasa.gov/ data). Geolocation products (MYD03) contain geodetic latitude, longitude, solar zenith angle, and solar azimuth angle of the pixel center ( $1 \mathrm{~km}$ at nadir), which was used for the calculation of local incidence angle.

\section{b. Aqua MODIS atmospheric products}

The Aqua MODIS level 2 product (MYD07_L2), at $5 \mathrm{~km} \times 5 \mathrm{~km}$ pixel resolution, was obtained online (https://ladsweb.nascom.nasa.gov/data). Aqua MODIS has been selected as the equatorial crossing time is close to local noon time when the sun is overhead and the intensity is maximum. The Aqua MODIS temperature and moisture profiles produced at 20 vertical levels with $5 \mathrm{~km} \times 5 \mathrm{~km}$ pixel resolution were used to compute the vapor pressure $(\mathrm{hPa})$, following Clausius-Clapeyron equation. The salient characteristics of MODIS sensor may be found in Barnes et al. (1998) and Hall et al. (2004).

\section{c. Aqua MODIS aerosol product}

Daily Aqua MODIS level 2 AOD product (MYD04_L2) of spatial resolution $10 \mathrm{~km} \times 10 \mathrm{~km}$ and $1-\mathrm{km}$ pixel accuracy was acquired from the Level-1 and Atmosphere Archive and Distribution System (LAADS) Distributed Active Archive Center (DAAC), located in the Goddard Space Flight Center in Greenbelt, Maryland (https:// ladsweb.nascom.nasa.gov/). Two of the parameters extracted include "deep blue aerosol optical depth" at $550 \mathrm{~nm}$ and "deep blue Ångström exponent" for land.

\section{d. Temperature anomaly data}

Time series temperature anomaly data were obtained from the National Climate Data Center (https:// www.ncdc.noaa.gov/sotc/global/) for the period 1880 to 2014 for selection of study years. Based on the above data 2014 was considered the warmest year of the last decade and 2008 is the coolest year. The month of January was preferred as maximum cloud-free pixels are available during this month and the solar elevation is low resulting in the better manifestation of terrain morphology.

\section{e. $D E M$}

SRTM DEM, at a spatial resolution of 3 arc s, was obtained online (http://srtm.usgs.gov). The data were used for the calculation of terrain slope and aspect direction. Sink and peak correction for the images was carried out to generate seamless DEM. The 3-arc-s DEM was considered to be optimum for features of subgrid scale wherein further disaggregation can be avoided. Ruiz-Arias et al. (2011) mentioned that highresolution DEM (3 arc s) does not add new information to reduce the uncertainty of incoming solar radiation estimates and disaggregation from 3 to 9 arc s yielded better results. Hence the grid resolution of $1 \mathrm{~km}$ was used to 1) represent average surface features around the radiometric stations, 2) minimize the uncertainty, and 3) ensure compatibility with MODIS geolocation products.

\section{f. Aeronet data}

Ground measured AOD (level 1.5, cloud screened) was obtained from the Aeronet Robotic Network (https:// aeronet.gsfc.nasa.gov). Out of five stations, only Kanpur $\left(26.513^{\circ} \mathrm{N}, 80.232^{\circ} \mathrm{E}\right)$, Jaipur $\left(26.906^{\circ} \mathrm{N}, 75.806^{\circ} \mathrm{E}\right)$, and 
Gandhi College $\left(25.871^{\circ} \mathrm{N}, 84.128^{\circ} \mathrm{E}\right)$ data were used because for rest of the stations the aerosol data of October 2008 and 2014 were not available. The data are available at different wavelengths, namely, 1640, 1020, 870, 675, 667, 555, 551, 531, 531, 500, 490, 443, $440,412,380$, and $340 \mathrm{~nm}$, of which only $500-\mathrm{nm}$ data were used for validation of MODIS aerosol optical depth at $500 \mathrm{~nm}$.

\section{g. Ground radiation data}

For validation of the MODIS derived instantaneous surface solar flux, a ground network of radiometric stations under Solar Radiation Resources Assessment (SRRA) project was used. SRRA project is an endeavor of National Institute of Solar Energy (NISE), Ministry of New and Renewable Energy, Government of India. The project was initiated in 2016 with the aim to measure global, diffuse and direct radiation using a tower-mounted $(1.5$ and $6 \mathrm{~m})$ solar tracker equipped with pyranometer, pyranometer with a shading disc, and pyrheliometer at 1-min interval. The quality criteria for generating global horizontal irradiance, direct normal irradiance, and diffuse horizontal irradiance was followed as per the standards by World Meteorological Organization elaborated by the Management and Exploitation of Solar Resources Knowledge (MESOR). The ground network consists of eight stations, namely, Bagora $\left(25.214^{\circ} \mathrm{N}, 72.018^{\circ} \mathrm{E}\right)$, Charanka $\left(23.893^{\circ} \mathrm{N}\right.$, $\left.71.212^{\circ} \mathrm{E}\right)$, Chennai $\left(12.956^{\circ} \mathrm{N}, 80.217^{\circ} \mathrm{E}\right)$, Erode $\left(11.27^{\circ} \mathrm{N}\right.$, $\left.77.604^{\circ} \mathrm{E}\right)$, Idar $\left(23.83^{\circ} \mathrm{N}, 73.003^{\circ} \mathrm{E}\right)$, Kadiri $\left(14.11^{\circ} \mathrm{N}\right.$, $\left.78.147^{\circ} \mathrm{E}\right)$, and Kotada Pitha $\left(21.948^{\circ} \mathrm{N}, 79.811^{\circ} \mathrm{E}\right)$. From daily data of 1-min temporal interval, only those datasets were chosen that are close to MODIS overpass time to avoid any discrepancy. The geographic locations of the ground radiometric stations with their altitude and aspect direction are given in Table 1.

\section{h. MERRA-2 data}

MERRA-2 is the latest atmospheric reanalysis of the modern satellite era produced by NASA's Global Modeling and Assimilation Office (Gelaro et al. 2017). The advancement of MERRA-2 over its predecessor include representation of stratosphere including ozone, improved representations of cryospheric processes, and reduced bias. MERRA-2 is the first long-term global reanalysis to assimilate space-based observations of aerosols and represent their interactions with other physical processes in the climate system. The products are accessible online through the NASA Goddard Earth Sciences Data and Information Services Center (GES DISC). The MERRA-2 web service provides time series of temperature (at $2 \mathrm{~m}$ ), relative humidity (at $2 \mathrm{~m}$ ), pressure (at $2 \mathrm{~m}$ ), wind speed and direction (at $10 \mathrm{~m}$ ),
TABLE 1. Location of the ground radiometric stations with their elevation and aspect values.

\begin{tabular}{clcccc}
\hline \hline $\begin{array}{c}\text { Station } \\
\text { No }\end{array}$ & Location & $\begin{array}{c}\text { Lat } \\
\left({ }^{\circ} \mathrm{N}\right)\end{array}$ & $\begin{array}{r}\text { Lon } \\
\left({ }^{\circ} \mathrm{E}\right)\end{array}$ & $\begin{array}{r}\text { Elevation } \\
(\mathrm{m})\end{array}$ & $\begin{array}{r}\text { Aspect } \\
\left({ }^{\circ}\right)\end{array}$ \\
\hline 1 & Bagora & 25.21 & 72.02 & 75 & 208 \\
2 & Charanka & 23.89 & 71.21 & 9 & 334 \\
3 & Chennai & 12.95 & 80.22 & 2 & 270 \\
4 & Erode & 11.27 & 77.60 & 270 & 42 \\
5 & Idar & 23.83 & 73.00 & 206 & 216 \\
6 & Kadiri & 14.11 & 78.15 & 518 & 342 \\
7 & Kotada Pitha & 21.95 & 71.21 & 206 & 178 \\
8 & Puducherry & 11.96 & 79.81 & 43 & 130 \\
\hline
\end{tabular}

rainfall, snowfall, and snow depth. Along with these parameters, broadband global horizontal irradiation (GHI) is also being provided at 1-min, 5-min, 10-min, 15-min, 30-min, hourly, daily, and monthly temporal intervals. In the present study, MERRA-2 data of 1-min interval were used as a proxy to ground radiation data, especially in the hilly regions. Six locations from each of the hilly physiographic regions were chosen to adequately represent the spatial variability of different aspect classes. The values of surface irradiance were extracted from each location (for both 2008 and 2014) to compare with the MODIS derived instantaneous surface solar flux.

\section{Methods}

\section{a. Estimation of instantaneous surface solar irradiance}

On an unobstructed slope, the direct flux from the sun is related to the cosine of the solar incident angle, defined as the angle between the direction of a solar beam and the normal vector of an inclined surface. The instantaneous solar irradiance at solar zenith angle $\left(\mathrm{SW}_{\downarrow \theta}\right)$ was estimated using Zillman (1972) parameterization scheme (Niemelä et al. 2001; Bisht et al. 2005) as follows:

$\mathrm{SW}_{\downarrow \theta}=S_{0} \cos ^{2} \theta /\left[1.085 \cos \theta+e_{0}(2.7+\cos \theta) 0.001+0.1\right]$,

where $S_{0}=1367 \mathrm{~W} \mathrm{~m}^{-2}$ is the solar constant and $\theta$ is the solar zenith angle, which has been taken from the Aqua MODIS geolocation product (MYD03) for each pixel. Actual columnar vapor pressure $e_{0}$ was calculated using the Clausius-Clapeyron equation (Rogers and Yau 1989) as follows:

$$
e_{0}=6.11 \exp \left[\frac{L_{v}}{R_{v}}\left(\frac{1}{T_{0}}-\frac{1}{T_{d}}\right)\right],
$$


where $L_{v}=2.5 \times 10^{6} \mathrm{~J} \mathrm{~kg}^{-1}$ is the latent heat of vaporization, $R_{v}=461 \mathrm{~J} \mathrm{~kg}^{-1} \mathrm{~K}^{-1}$ is the gas constant for water vapor, $T_{0}=273 \mathrm{~K}$, and $T_{d}$ is the dewpoint temperature. In this study, $e_{0}$ was calculated at every level and then vertically averaged to generate columnintegrated values (20 vertical levels; $\mathrm{hPa}$ ).

To account for the effect of topography in the Eq. (1), solar zenith angle $\theta$ was replaced with local incidence angle $i$, which is the angle between the incident sun rays and normal to the surface (Gates 1980):

$$
\cos i=\sin \varphi \cos a \cos \left(\alpha-\alpha_{s}\right)+\cos \varphi \sin a,
$$

where $\varphi$ is the surface slope angle, $a$ is the elevation angle of the sun, $\alpha$ is the azimuth angle of the sun, and $\alpha_{s}$ is the aspect of the surface. Here, the slope and aspect have been generated from the SRTM DEM of 90-m data and resampled the gridded data to a $1-\mathrm{km}$ grid using the nearest-neighborhood interpolation technique.

By introducing the cosi in Eq. (1) it can be rewritten as

$$
\mathrm{SW}_{\downarrow i}=S_{0} \cos ^{2} i /\left[1.085 \cos i+e_{0}(2.7+\cos i) 0.001+0.1\right] .
$$

\section{b. Calculation of transmittance due to aerosol extinction}

The transmittance due to aerosol extinction $T_{a}$ is given by Yang et al. (2006) as follows:

$$
\begin{aligned}
T_{a}= & \exp \{-m \beta[0.6777+0.1464(m \beta) \\
& \left.\left.-0.00626(m \beta)^{2}\right]^{-1.3}\right\}
\end{aligned}
$$

where $T_{a}$ is the broadband radiative transmittance due to aerosol extinction, $m=1 / \cos \theta$ (where $\theta$ is the zenith angle) is the air mass, and $\beta$ is the Angström turbidity coefficient.

Ångström turbidity coefficient $\beta$ is a constant parameter defining the amount of aerosol in the air and can be estimated using the Ångström turbidity formula [Eq. (6)], where the wavelength, aerosol optical depth, Ångström exponent, and turbidity coefficient are related with each other. Thus, the spectral dependence of aerosol optical depth at any wavelength can be expressed as follows (Yang et al. 2006):

$$
\tau_{\lambda}=\beta \lambda^{-\alpha}
$$

or

$$
\beta=\tau_{\lambda 1} /\left(\lambda_{1}^{-\alpha}\right)=\tau_{\lambda 2} /\left(\lambda_{2}^{-\alpha}\right)
$$

where $\lambda$ is the wavelength $(\mu \mathrm{m}), \tau_{\lambda}$ is the aerosol optical depth at a given wavelength $\lambda, \beta$ is the Ångström turbidity coefficient, and $\alpha$ is the Ångström exponent.

This model (Yang et al. 2006) model utilizes aerosol optical depth at $500 \mathrm{~nm}\left(\tau_{0.5}\right)$ but MODIS products provides optical depth at $550 \mathrm{~nm}\left(\tau_{0.55}\right)$. Hence aerosol optical depth at $500 \mathrm{~nm}$ was generated using the following formula:

$$
\tau_{0.50}=\tau_{0.55}(0.5 / 0.55)^{-\alpha}
$$

or

$$
\alpha=-\ln \left(\tau_{0.55} / \tau_{0.5}\right) / \ln (0.55 / 0.50) .
$$

The value of $\alpha$ was directly taken from MYD04_L2 product.

\section{SOLVING FOR $\beta$}

$$
\begin{aligned}
\beta & =\tau_{1} \lambda_{1}^{a}=\tau_{2} \lambda_{2}^{a} \\
& =\tau_{0.5} \times 0.5^{\alpha} .
\end{aligned}
$$

The turbidity coefficient $\beta$ is related to the aerosols content, whereas the wavelength exponent $\alpha$ is related to the size distribution of particles (Ångström 1964). In the Yang model [Eq. (5)], the Ångström exponent was assumed as a constant (1.3; average for natural atmosphere) but in the present study, the value has been replaced with $\alpha$ values from MODIS_L2 products.

\section{c. Calculation of aerosol-corrected instantaneous surface irradiance}

The aerosol-corrected instantaneous surface irradiance at the local incidence angle $\left(\mathrm{SW}_{\downarrow i-T_{a}}\right)$ can be estimated using Eqs. (4) and (8) as follows:

$$
\mathrm{SW}_{\downarrow i-T_{a}}=T_{a} \mathrm{SW}_{\downarrow i} .
$$

\section{d. Statistical analysis}

For validation, the modeled shortwave flux was compared with observed flux (SOLINDIA ground radiation data) and MERRA-2 data using coefficient of determination $R^{2}$, root-mean-square error (RMSE), relative RMSE, coefficient of residual mass (CRM), and modeling efficiency (ME) to evaluate the errors in the modeled irradiance. The formula of different statistical parameters is given below:

$$
\mathrm{RMSE}=\sqrt{\frac{1}{n} \sum_{i=1}^{n}\left(P_{i}-O_{i}\right)^{2}},
$$

Relative RMSE $=\frac{1}{\bar{O}} \sqrt{\frac{1}{n} \sum_{i=1}^{n}\left(P_{i}-O_{i}\right)^{2}}$, 
TABLE 2. Mean monthly (January) surface solar irradiance $\left(\mathrm{W} \mathrm{m}^{-2}\right)$ estimated by different methods. Values in parentheses represent one standard deviation.

\begin{tabular}{|c|c|c|c|c|c|c|}
\hline \multirow[b]{3}{*}{ PSD } & \multicolumn{6}{|c|}{ Surface solar irradiance } \\
\hline & \multicolumn{3}{|c|}{2008} & \multicolumn{3}{|c|}{2014} \\
\hline & Basic & Orography-corrected & $\begin{array}{c}\text { Orography }+ \\
\text { aerosol-corrected }\end{array}$ & Basic & Orography-corrected & $\begin{array}{c}\text { Orography }+ \\
\text { aerosol-corrected }\end{array}$ \\
\hline Western Himalayas & $702( \pm 46)$ & $697( \pm 43)$ & $659( \pm 73)$ & $677( \pm 47)$ & $691( \pm 38)$ & $660( \pm 172)$ \\
\hline Central Himalayas & $754( \pm 44)$ & $758( \pm 35)$ & $657( \pm 97)$ & $746( \pm 42)$ & $755( \pm 37)$ & $687( \pm 158)$ \\
\hline Eastern Himalayas & $763( \pm 48)$ & $770( \pm 46)$ & $722( \pm 62)$ & $756( \pm 43)$ & $764( \pm 38)$ & $731( \pm 167)$ \\
\hline Western Hills & $918( \pm 45)$ & $872( \pm 45)$ & $580( \pm 135)$ & $904( \pm 48)$ & $904( \pm 48)$ & $757( \pm 95)$ \\
\hline Eastern Hills & $876( \pm 40)$ & $856( \pm 29)$ & $644( \pm 110)$ & $867( \pm 39)$ & $864( \pm 38)$ & $726( \pm 77)$ \\
\hline North Eastern Range & $771( \pm 49)$ & $751( \pm 50)$ & $588( \pm 102)$ & $760( \pm 48)$ & $756( \pm 47)$ & $592( \pm 108)$ \\
\hline North Deccan & $843( \pm 38)$ & $838( \pm 36)$ & $446( \pm 69)$ & $830( \pm 40)$ & $830( \pm 40)$ & $634( \pm 62)$ \\
\hline South Deccan & $887( \pm 45)$ & $889( \pm 39)$ & $565( \pm 120)$ & $876( \pm 43)$ & $875( \pm 43)$ & $696( \pm 61)$ \\
\hline Central Highlands & $791( \pm 37)$ & $788( \pm 39)$ & $460( \pm 107)$ & $776( \pm 43)$ & $776( \pm 43)$ & $594( \pm 43)$ \\
\hline Eastern Plateau & $815( \pm 35)$ & $823( \pm 41)$ & $513( \pm 133)$ & $804( \pm 41)$ & $803( \pm 41)$ & $580( \pm 60)$ \\
\hline Western Plain & $773( \pm 34)$ & $763( \pm 44)$ & $561( \pm 131)$ & $760( \pm 40)$ & $760( \pm 40)$ & $562( \pm 46)$ \\
\hline Northern Plain & $740( \pm 40)$ & $726( \pm 42)$ & $424( \pm 138)$ & $725( \pm 47)$ & $726( \pm 47)$ & $569( \pm 64)$ \\
\hline Eastern Plain & $771( \pm 58)$ & $772( \pm 41)$ & $466( \pm 160)$ & $769( \pm 47)$ & $767( \pm 45)$ & $567( \pm 76)$ \\
\hline West Coast Plain & $844( \pm 38)$ & $831( \pm 51)$ & $634( \pm 117)$ & $836( \pm 44)$ & $834( \pm 43)$ & $659( \pm 107)$ \\
\hline East Coast Plain & $858( \pm 42)$ & $833( \pm 30)$ & $696( \pm 106)$ & $854( \pm 41)$ & $849( \pm 41)$ & $788( \pm 125)$ \\
\hline Mean of all PSDs & 807 & 798 & 574 & 796 & 797 & 653 \\
\hline
\end{tabular}

$$
\begin{gathered}
\mathrm{CRM}=\frac{\sum_{i=1}^{n} O_{i}-\sum_{i=1}^{n} P_{i}}{\sum_{i=1}^{n} O_{i}}, \\
\mathrm{ME}=1-\frac{\sum_{i=1}^{n}\left(P_{i}-O_{i}\right)^{2}}{\sum_{i=1}^{n}\left(P_{i}-\bar{O}\right)^{2}},
\end{gathered}
$$

where $P_{i}$ is the modeled value, $O_{i}$ is the observed value, $\bar{O}$ is the observed mean, $P_{i}^{\prime}=P_{i}-\bar{O}, O_{i}^{\prime}=O_{i}-\bar{O}$, and $n$ is the number of observations. For details, see Willmott (1982) and Kobayashi and Salam (2000). The negative CRM value indicates that the majority of simulated values are greater than the observed values and vice versa, (Smith et al. 1996; Loague and Green 1991). The ME is sensitive to extreme values and might yield suboptimal results when the dataset contains large outliers. For a perfect match, the ME value is 1 . Essentially, the closer the model efficiency is to 1 , the more accurate is the model.

\section{Results and discussion}

\section{a. MODIS derived instantaneous surface solar irradiance}

Instantaneous shortwave flux for all the dates of January (2008 and 2014) was estimated using solar zenith angle $\left(\mathrm{SW}_{\downarrow}\right.$; , hereafter "basic"), local incidence angle ( $\mathrm{SW}_{\downarrow}$; hereafter "orography-corrected"), and "orography + aerosol-corrected" (Table 2). There is a good agreement between both basic and orographycorrected methods. In general, surface irradiance is minimum in Western Himalayas and Northern Plain in both the years and maximum in South Deccan and Western Hills (Table 2). The basic shortwave flux varies from 702 to $918 \mathrm{~W} \mathrm{~m}^{-2}$ among different PSDs with a monthly mean, computed over all the PSDs, of $807 \mathrm{~W} \mathrm{~m}^{-2}$ in 2008 and 677 to $904 \mathrm{~W} \mathrm{~m}^{-2}$ with a mean of $796 \mathrm{~W} \mathrm{~m}^{-2}$ in 2014. Considering all the PSDs the shortwave flux did not change much when the orography was considered in the calculation. The mean differences between basic and orography-corrected shortwave flux is only 9 and $1 \mathrm{~W} \mathrm{~m}^{-2}$ in 2008 and 2014, respectively, as is evident from Table 2 mean values. However, large variation was observed between former and orography + aerosol-corrected values (more than $28 \%$ and $17 \%$ in 2008 and 2014, respectively).

Spatial distribution of instantaneous mean monthly surface irradiance depicts the latitudinal variation wherein there is a gradual decrease in shortwave flux from south-to-north direction (Fig. 2). Figure 2 depicts instantaneous shortwave flux by all the three methods (basic, orography-corrected, and orography + aerosolcorrected) implemented in the study. The latitudinal variation is prominent in basic (Figs. 2a,d) and orographycorrected (Figs. 2b,e) methods in both the years. But the gradient is interrupted (Figs. 2c,f) when aerosol transmittance is superimposed onto the orography-corrected image, which will be discussed in the next section. In the 

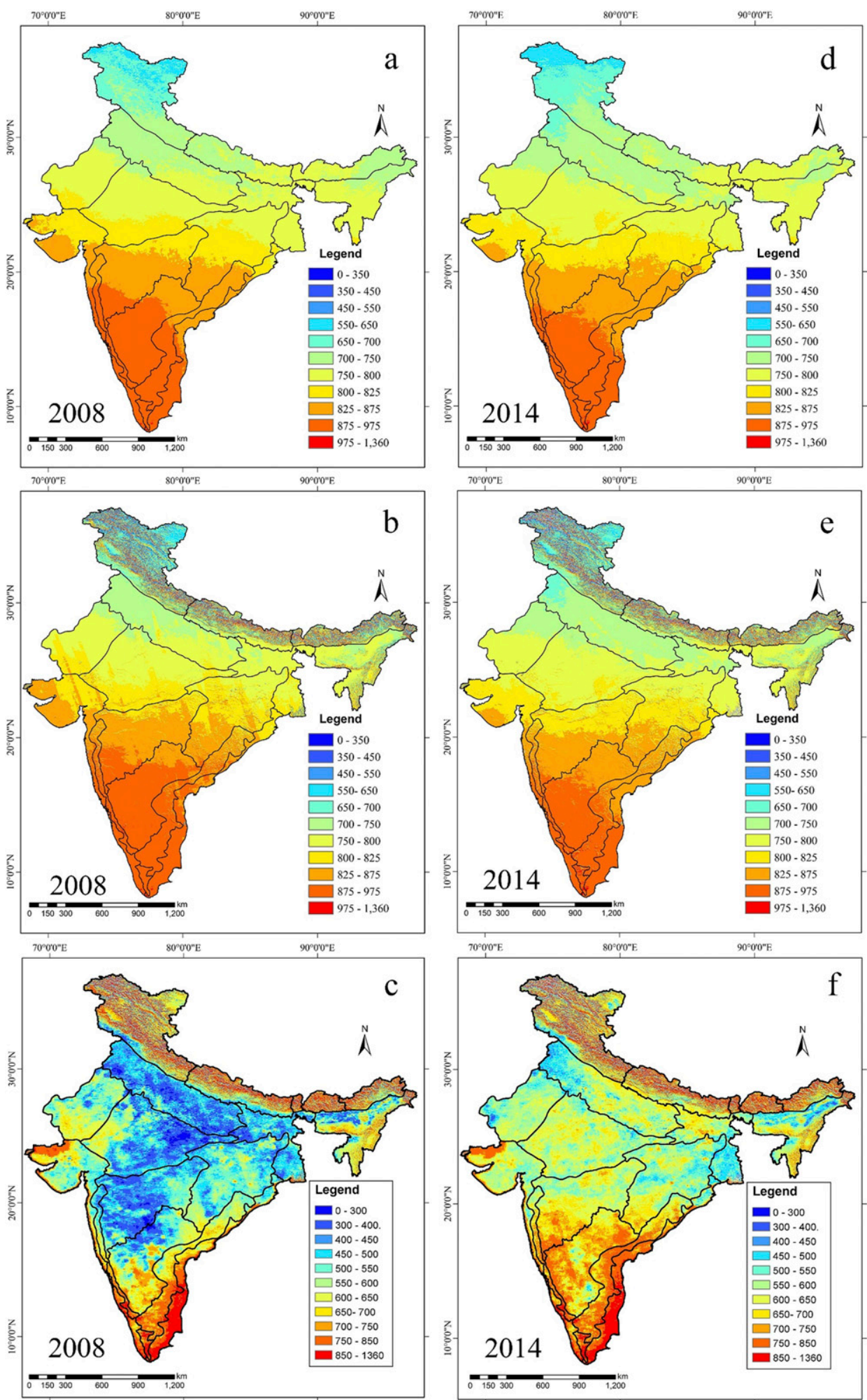

FIG. 2. Mean monthly (January) surface solar irradiance (left) in 2008 by (a) basic, (b) orographycorrected, and (c) orography + aerosol-corrected methods and (right) in 2014 by (d) basic, (e) orography corrected, and (f) orography + aerosol-corrected methods. 
TABLE 3. Mean monthly (January) aerosol transmittance over different PSDs. Minimum, maximum, and mean [plus and minus one standard deviation (SD)] values correspond to each subdivision over all the days of January.

\begin{tabular}{|c|c|c|c|c|c|c|}
\hline \multirow[b]{2}{*}{ PSD } & \multicolumn{3}{|c|}{2008} & \multicolumn{3}{|c|}{2014} \\
\hline & Min & Max & Mean \pm SD & Min & $\operatorname{Max}$ & Mean \pm SD \\
\hline Western Himalayas & 0.14 & 0.86 & $0.67 \pm 0.15$ & 0.34 & 0.85 & $0.72 \pm 0.11$ \\
\hline Central Himalayas & 0.31 & 0.90 & $0.70 \pm 0.16$ & 0.40 & 0.91 & $0.72 \pm 0.12$ \\
\hline Eastern Himalayas & 0.36 & 0.88 & $0.80 \pm 0.09$ & 0.40 & 0.88 & $0.80 \pm 0.09$ \\
\hline Western Hills & 0.37 & 0.85 & $0.64 \pm 0.11$ & 0.45 & 0.85 & $0.66 \pm 0.06$ \\
\hline Eastern Hills & 0.39 & 0.89 & $0.67 \pm 0.06$ & 0.34 & 0.88 & $0.63 \pm 0.06$ \\
\hline North Eastern Range & 0.14 & 0.86 & $0.63 \pm 0.17$ & 0.15 & 0.88 & $0.66 \pm 0.14$ \\
\hline North Deccan & 0.24 & 0.72 & $0.46 \pm 0.09$ & 0.38 & 0.74 & $0.61 \pm 0.04$ \\
\hline South Deccan & 0.24 & 0.85 & $0.57 \pm 0.13$ & 0.34 & 0.82 & $0.62 \pm 0.07$ \\
\hline Central Highlands & 0.21 & 0.76 & $0.46 \pm 0.12$ & 0.44 & 0.77 & $0.64 \pm 0.06$ \\
\hline Eastern Plateau & 0.34 & 0.76 & $0.56 \pm 0.07$ & 0.42 & 0.79 & $0.60 \pm 0.05$ \\
\hline Western Plain & 0.27 & 0.76 & $0.60 \pm 0.10$ & 0.30 & 0.75 & $0.67 \pm 0.06$ \\
\hline Northern Plain & 0.25 & 0.66 & $0.43 \pm 0.08$ & 0.31 & 0.70 & $0.52 \pm 0.06$ \\
\hline Eastern Plain & 0.29 & 0.68 & $0.47 \pm 0.05$ & 0.22 & 0.67 & $0.53 \pm 0.05$ \\
\hline West Coast Plain & 0.15 & 0.82 & $0.62 \pm 0.08$ & 0.34 & 0.81 & $0.65 \pm 0.05$ \\
\hline East Coast Plain & 0.35 & 0.77 & $0.64 \pm 0.07$ & 0.27 & 0.77 & $0.63 \pm 0.07$ \\
\hline
\end{tabular}

basic method, the terrain effect on surface irradiance is absent but in orography-corrected method the variability of shortwave flux with surface orientation is distinct in the Himalayan regions. The latitudinal variation is due to the orientation of Earth relative to the sun. The sun's rays strike Earth surface more directly and focused way at the equator whereas at high latitudes (near the poles), it falls on the surface at a more oblique angle and the energy spreads over a wide area. Hence the average amount of incoming solar radiation decreases from the equator to the higher latitudes. The secondary reason could be the larger optical pathlength for higher latitudes resulting in more scattering and absorption of solar energy. Figure 2 depicts the spatial variability of the shortwave flux computed by basic, orography-corrected, and topography + aerosol-corrected methods. The left side of the figure shows the shortwave flux in 2008 and the right side depicts shortwave flux in 2014. The latitudinal gradient is evident in basic and orographycorrected images in both the years (Figs. 2a,b,d,e). The magnitude of shortwave flux decreases with increasing latitudes. The major difference of orography-corrected shortwave flux with the basic is the effect of surface topography in the Himalayan region and North Eastern Hills. A very high-density solar energy pocket (875$975 \mathrm{~W} \mathrm{~m}^{-2}$ ) including the southern half of South Deccan, south of North Deccan, Eastern Hills, East Coastal Plain, and Western Hills gives rise to a conspicuous oval shape (Figs. 2a,b,d,e) bordering the lower half of the west coast and east coast. This pocket is somewhat pushed to south during 2014. Similar observations were reported by Vyas et al. (2016). The other sources exhibit similar pattern include Clouds and the Earth's Radiant Energy System (CERES) monthly solar insolation product of $0.25^{\circ}$ graticule also and the National Renewable Energy Laboratory (NREL) model estimated monthly average direct normal irradiance map (not shown here) for winter months. The highdensity energy pocket could be due to the tilt of the axis of the sun, which is changing the sun position (sun path), orography ( $>600 \mathrm{~m}$ above mean sea level), and composition of the atmosphere; especially during January, columnar water vapor will be less as the surface temperature is very low due to elevation and season.

The instantaneous surface irradiance varied between 700 and $825 \mathrm{~W} \mathrm{~m}^{-2}$ in most of the areas of the Western Plain, Northern Plain (except northwestern part), Central Highlands, the upper half of the Eastern Plateau, the northern part of the North Deccan, and south of the Eastern Plain. In northern India, low shortwave flux of $650-700 \mathrm{~W} \mathrm{~m}^{-2}$ is discernible in the western half of the state of Punjab during 2014 but not in 2008. The latitudinal gradient of shortwave flux is interrupted by the orographic variations over the Himalayan regions and this can be seen in Figs. 2b and 2e. Very high shortwave flux values over the Himalayan region could be due to the high elevation resulting in a clear atmosphere, shorter optical pathlength, and aspect direction.

\section{b. Transmittance due to aerosol extinction}

To account for the contribution of columnar aerosol on solar irradiance, aerosol transmittance $T_{a}$ was computed using the Ångström turbidity coefficient $\beta$ using Eq. (10) and the Angström exponent $\alpha$ from MODIS level 2 AOD product.

Aerosol loading, in general, is medium to low in both the years except for the Indo-Gangetic region (consisting of the Northern Plain and Eastern Plain) (Table 3), 
which could be due to absorbing haze, biomass burning, and enhanced dust transport extending from the Southwest Asian arid regions into the Indo-Gangetic Plain (Gautam et al. 2011). High values of aerosols in these regions have also been reported by several authors (Massie et al. 2004; Prasad et al. 2004, 2006; Ramachandran and Cherian 2008; Ramachandran et al. 2012; Babu et al. 2013; Kumar et al. 2014). Besides the Indo-Gangetic region, the North Deccan and Central Highlands also exhibited high aerosol loading in 2008 (Table 3). The mean monthly value of $T_{a}$ over the entire study region during 2008 was little lower $(0.59 \pm 0.1)$ than during $2014(0.64 \pm 0.07)$. But significant variation in $T_{a}$ was observed among all the PSDs in both the years. Lowest values of mean $T_{a}$ were observed over the Northern Plain both in 2008 and in 2014 (Table 3), the values of which are $0.43( \pm 0.08)$ and $0.52( \pm 0.06)$, respectively. In contrast, the Eastern Himalayas exhibited the highest value of $T_{a}(0.80 \pm 0.09)$ in both the years. In 2008 the area of high aerosol loading is extended in the south direction covering the Central Highlands, North Deccan, and north of South Deccan (not shown here). A narrow belt of high transmittance $(\sim 0.95)$ was observed along the foothills of the Himalayan region extending from Jammu and Kashmir to the North Eastern states of Arunachal Pradesh, Nagaland, Mizoram, and Manipur, and parts of Meghalaya except for the state of Assam. In the southern half of India some isolated pockets of high $T_{a}(>0.80)$ were observed in the South Deccan, Eastern Hills, and Western Hills regions. The Ångström exponent $\alpha$, which is a representative of the aerosol size distribution, showed low values $(1.21 \pm 0.22)$ in 2008 over the most of North and South Deccan and the Central Highlands as well as scattered areas over the Northern Plain, which could be due to dominance of fine mode aerosols, probably the black carbon soot from biomass burning. During 2014, on the other hand, most of the area consists of high $\alpha(>1.5)$ except for some scattered portion of the South Deccan (not shown here). Spatial variability in the AOD and Ångström exponent tends to give rise significant differential radiative impact in the regions, which may affect the atmospheric dynamics and also influence the extreme events (Srivastava 2017).

Figures $2 \mathrm{c}$ and $2 \mathrm{f}$ depicts the orography + aerosolcorrected surface solar irradiance. The values were substantially reduced $\left(223 \mathrm{~W} \mathrm{~m}^{-2}\right.$ in 2008 and $143 \mathrm{~W} \mathrm{~m}^{-2}$ in 2014) due to incorporation of aerosol transmittance in the model (Table 2). In the higher elevations of the Western and Eastern Himalayas, the difference is less than $50 \mathrm{~W} \mathrm{~m}^{-2}$, which could be due to a shorter pathlength and less absorption and scattering by the atmospheric constituents including aerosols. The low value could also be due to fewer cloud-free pixels were available in MODIS data over the Western Hills and Eastern Himalayas. Among different PSDs, the aerosol forcing on surface solar irradiance is maximum $\left(>300 \mathrm{~W} \mathrm{~m}^{-2}\right)$ over the North Deccan, Central Highlands, Eastern Plateau, Eastern Plain, and Northern Plain in 2008; however, the magnitude is much lower in 2014 (ranges between 31 and $223 \mathrm{~W} \mathrm{~m}^{-2}$ ). It is interesting to note that the southern hotspot Figs. $2 \mathrm{e}$ and $2 \mathrm{f}$ is disintegrated after the introduction of aerosol correction. Another interesting feature is very high instantaneous surface irradiance in the West Coastal Plain, consisting of extensive salt pan of north Gujarat, the reason of which is not clearly known. The mean monthly value of daily terrainand aerosol-corrected instantaneous surface irradiance values in 2008 and 2014 are in agreement with the coldest (2008) and hottest (2014) year of the last decade as described by the National Climate Data Center. From Figs. 2e and 2f it is also evident that most of the Northern Plain, Central Highlands, North Deccan, Eastern Plain, north of South Deccan, and part of Eastern Plateau in 2008 had irradiance values ranging between 300 and $550 \mathrm{~W} \mathrm{~m}^{-2}$, which is much lower than 2014 when it varied between 650 and $825 \mathrm{~W} \mathrm{~m}^{-2}$. This large variation could be due to persistent occurrence of fog and haze in the Northern Plain including the Indo-Gangetic Plain during winter, which further extends to the Central Highlands. This problem is further aggravated due to extensive crop residue burning in the agricultural fields.

\section{c. Effect of surface topography on solar irradiance}

Under clear-sky conditions, the spatial variability of shortwave flux in the hilly terrain is primarily determined by topography including elevation and orientation (Becker and Boyd 1957). The hill surfaces that face the sun receive much greater irradiance and the irradiance pattern distribution along with the region changes according to the sun's position (Ruiz-Arias et al. 2011). Senkova et al. (2007) have mentioned that the orographic effects of surface radiation in a location are influenced by the elevation, horizon steepness and direction of surrounding slopes. In the present study orographic effects have been considered through elevation, slope angle, and the aspect of the surface. However, the relief shadow fraction and sky view factor was not considered as at local noon (MODIS overpass time) their effect is minimum (Ruiz-Arias et al. 2011).

To examine the topographic influence on shortwave flux, six PSDs, with predominantly hilly and rugged terrain, were selected. These regions include the Western Himalayas, Central Himalayas, Eastern Himalayas, North Eastern Range, Western Hills, and Eastern Hills, characterized by variable slope, aspect, and elevation. 

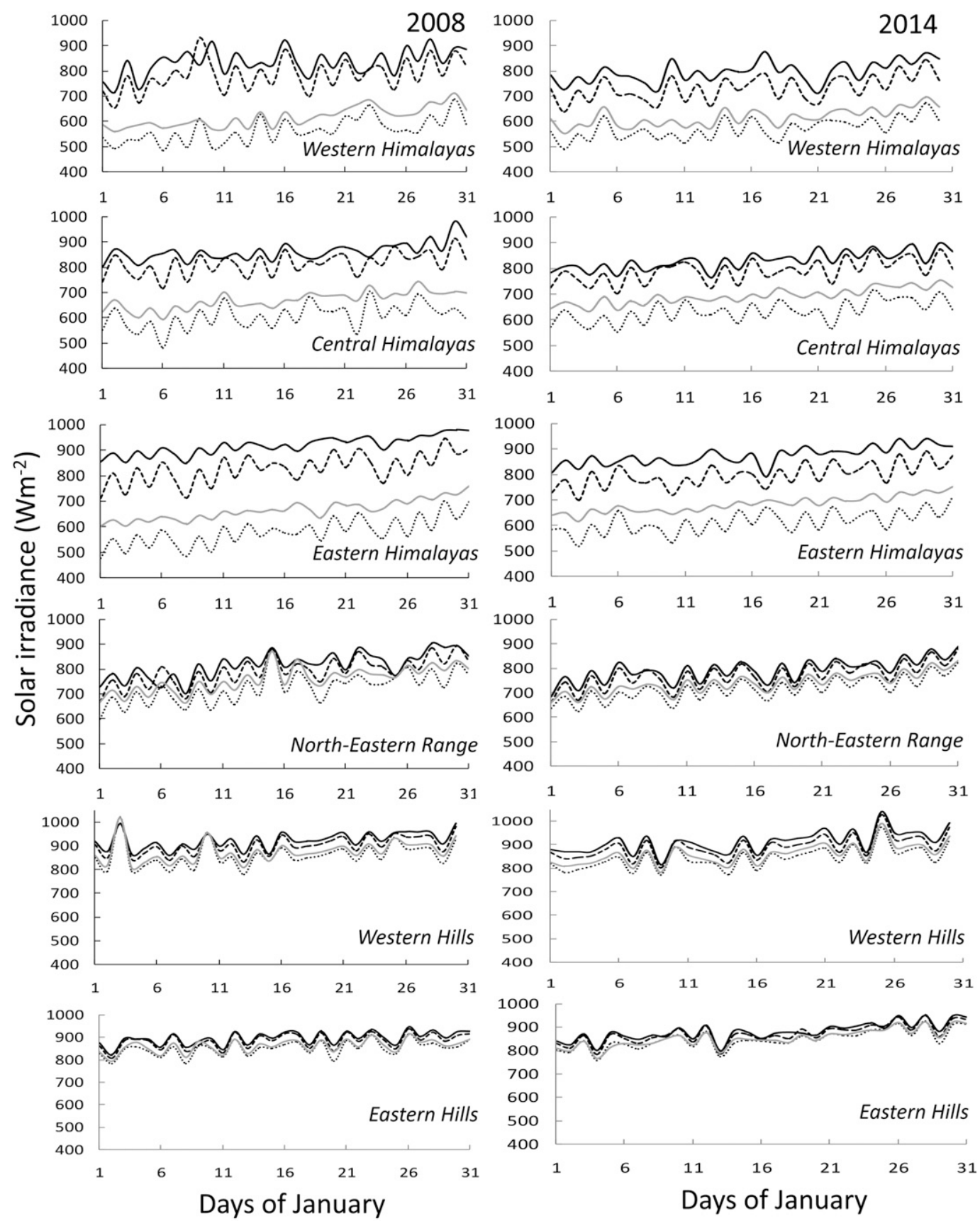

NE

SE SW NW

FIG. 3. Variation in solar irradiance with aspect directions over different physiographic subdivisions.

The original values of aspect angles $\left(0^{\circ}-360^{\circ}\right)$ were grouped into four categories, namely, $0^{\circ}-90^{\circ}(\mathrm{NE}), 90^{\circ}$ $180^{\circ}(\mathrm{SE}), 180^{\circ}-270^{\circ}(\mathrm{SW})$, and $270^{\circ}-360^{\circ}(\mathrm{NW})$. The effect of surface orientation on instantaneous surface irradiance was significant among the PSDs, accounting for 161 and $135 \mathrm{~W} \mathrm{~m}^{-2}$ in 2008 and 2014 , respectively (Fig. 3). The maximum variation was observed over the Eastern Himalayas in both the years, the values of which are 327 and $256 \mathrm{~W} \mathrm{~m}^{-2}$ in 2008 and 2014, respectively (Table 4); this may be due to a higher elevation (mean value of $2.39 \mathrm{~km}$ ), abundance of SW slope direction $(35.7 \%)$, and low aerosol loading. This difference in surface flux deviations at local scale may trigger more convection and small-scale circulations (Lee et al. 2013), which have an implication on climate modeling. In contrast the difference is significantly less $\left(<28 \mathrm{~W} \mathrm{~m}^{-2}\right)$ 
TABLE 4. Variability of mean monthly (January) orography + aerosol-corrected surface solar irradiance $\left(\mathrm{W} \mathrm{m}^{-2}\right)$ with aspect direction.

\begin{tabular}{|c|c|c|c|c|c|c|c|c|c|c|c|}
\hline \multirow[b]{2}{*}{ PSD } & \multirow[b]{2}{*}{ Elevation $(\mathrm{km})$ : mean \pm SD } & \multicolumn{5}{|c|}{2008} & \multicolumn{5}{|c|}{2014} \\
\hline & & $\mathrm{NE}$ & SE & SW & NW & Max minus min & $\mathrm{NE}$ & SE & SW & NW & Max minus min \\
\hline Western Himalayas & $3.66 \pm 1.65$ & 509 & 731 & 790 & 564 & 281 & 536 & 709 & 771 & 590 & 235 \\
\hline Central Himalayas & $2.12 \pm 1.77$ & 519 & 707 & 732 & 582 & 213 & 560 & 723 & 762 & 623 & 202 \\
\hline Eastern Himalayas & $2.39 \pm 1.37$ & 535 & 775 & 862 & 621 & 327 & 586 & 765 & 843 & 659 & 257 \\
\hline North Eastern Range & $0.57 \pm 0.70$ & 552 & 600 & 619 & 574 & 67 & 565 & 601 & 619 & 578 & 54 \\
\hline Western Hills & $0.61 \pm 0.35$ & 549 & 587 & 603 & 572 & 54 & 737 & 768 & 775 & 743 & 38 \\
\hline Eastern Hills & $0.42 \pm 0.30$ & 631 & 653 & 656 & 632 & 25 & 712 & 734 & 739 & 715 & 27 \\
\hline
\end{tabular}

in the Eastern Hills. The reasons could be low elevation $(0.42 \mathrm{~km})$, high aerosol loading (transmittance value $<0.3$ ), and less abundance of SW slope direction $(21.6 \%)$. However, relative abundance of SW aspect may not be the reason for large variability in surface irradiance as in the North Eastern region and Western Hills the proportion of SW slope is very high $(29.5 \%$ and $26.1 \%$, respectively) but the difference in surface irradiance among different aspect classes is very low. Less variability of surface radiative flux on the Eastern Hills, Western Hills, and North Eastern Range compared to other Himalayan regions could be due to its north-south orientation and low elevation.

Based upon the magnitude of difference in surface solar irradiance among different aspect classes, all hilly PSDs can be grouped into two classes, namely, 1) more than $200 \mathrm{~W} \mathrm{~m}^{-2}$ (Western Himalayas, Central Himalayas, Eastern Himalayas) and 2) less than $100 \mathrm{~W} \mathrm{~m}^{-2}$ (North Eastern Range, Western Hills, Eastern Hills) (Table 4). From the relative distribution of different aspect classes, it is expected that the Eastern Himalayas and Central Himalayan regions will intercept more surface irradiance in comparison to the Western Himalayas, North Eastern Range, Western Hills, and Eastern Hills. However, the slope factor is very sensitive to surface orientation and small uncertainty in the aspect will produce a large uncertainty in incoming irradiance, depending on solar zenith angle (Ruiz-Arias et al. 2011). The numerical derivation of the topographic parameters produces a stochastic component that is transferred to the solar irradiance estimation (Ruiz-Arias et al. 2011) and hence accurate assessment of the irradiance on an inclined surface demands very precise measurements of the surface orientation (Tovar-Pescador et al. 2006).

\section{d. Validation of the MODIS derived $A O D$ at $500 \mathrm{~nm}$ with Aeronet AOD $(500 \mathrm{~nm})$ data}

The uncertainty of the MODIS derived AOD at $500 \mathrm{~nm}\left(\tau_{0.5}\right)$ was determined using limited data available from Aeronet. Aeronet data of Jaipur, Kanpur, and Gandhi College at $500 \mathrm{~nm}$ were used. MODIS AOD showed good agreement (Fig. 4) with the Aeronet data with an $R^{2}$ value of 0.875 (significant at the $1 \%$ level) and an RMSE of 0.12 .

\section{e. Validation of orography + aerosol-corrected surface solar irradiance with ground radiation data and MERRA-2 data}

To examine the accuracy of the present model, the MODIS derived surface solar radiance was compared with SRRA radiation data collocated in time and space. Six statistical parameters were used for comparisons, namely, $R^{2}$, RMSE, relative RMSE, CRM, and ME. Modeled shortwave flux (basic, orography-corrected, and orography + aerosol-corrected) was validated using available ground measured data and MERRA-2 data (Fig. 5). Figures 5a-c depict the scatterplot between modeled shortwave flux by basic, orography-corrected, and orography + aerosol-corrected methods and groundmeasured surface irradiance, respectively. In the right panels Figs. 5d-f show the scatterplot between modeled shortwave flux and MERRA-2 data. Although the $R^{2}$ value of basic and orography-corrected shortwave flux is significant with measured radiation data, but the RMSE is very high (184 and $187 \mathrm{~W} \mathrm{~m}^{-2}$, respectively).

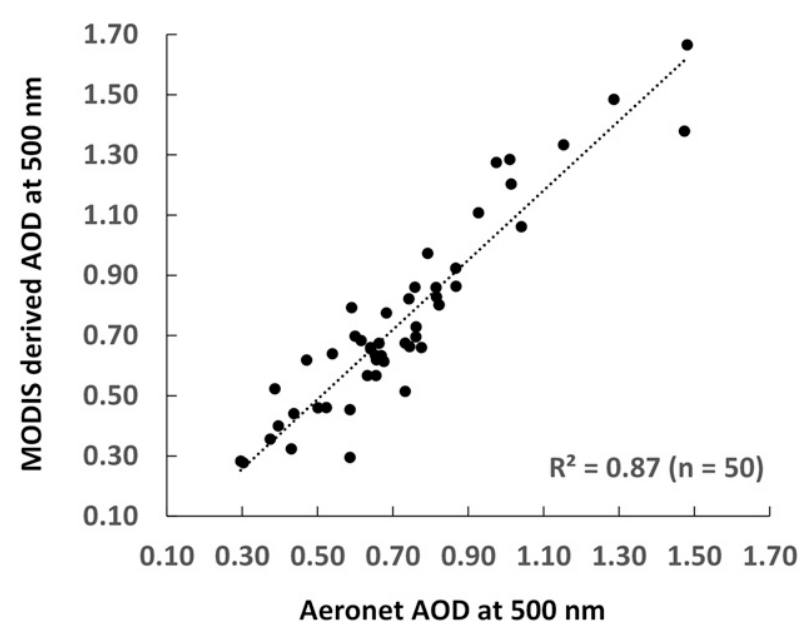

FIG. 4. Scatterplot between Aeronet AOD and MODIS-derived $\mathrm{AOD}$ at $500 \mathrm{~nm}$. 


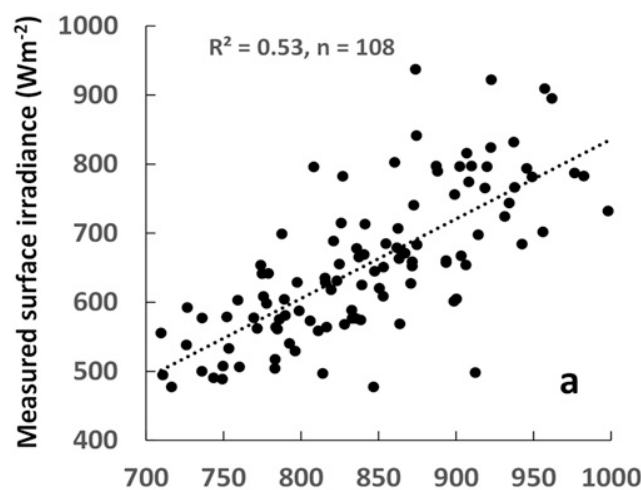

Zenith angle based surface irradiance $\left(\mathrm{Wm}^{-2}\right)$

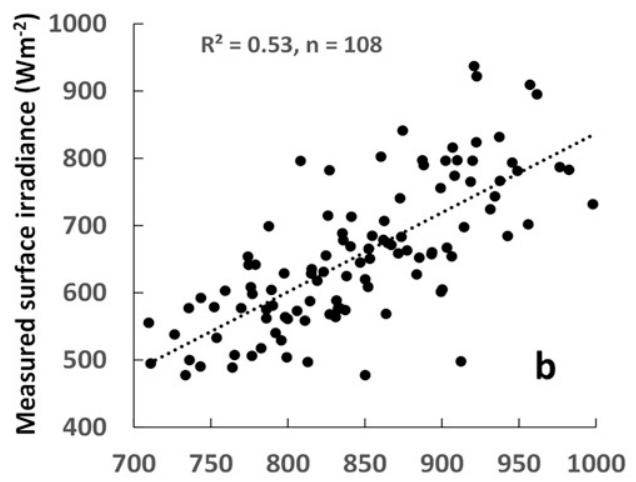

Incidence angle based surface irradiance $\left(\mathrm{Wm}^{-2}\right)$

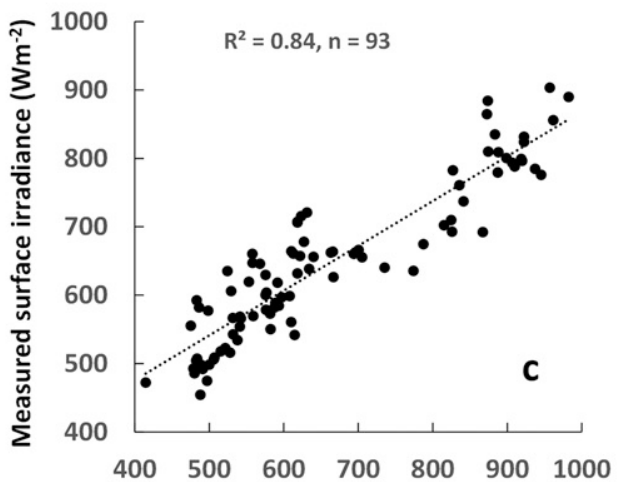

Orography+aerosol corrected irradiance $\left(\mathrm{Wm}^{-2}\right)$

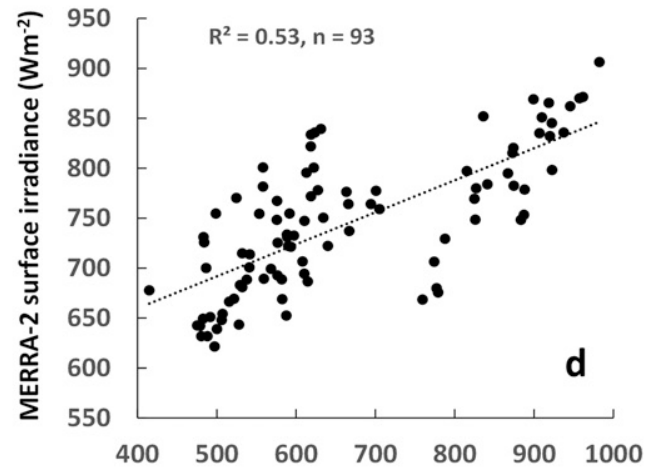

Orography+aerosol corrected irradiance $\left(\mathrm{Wm}^{-2}\right)$
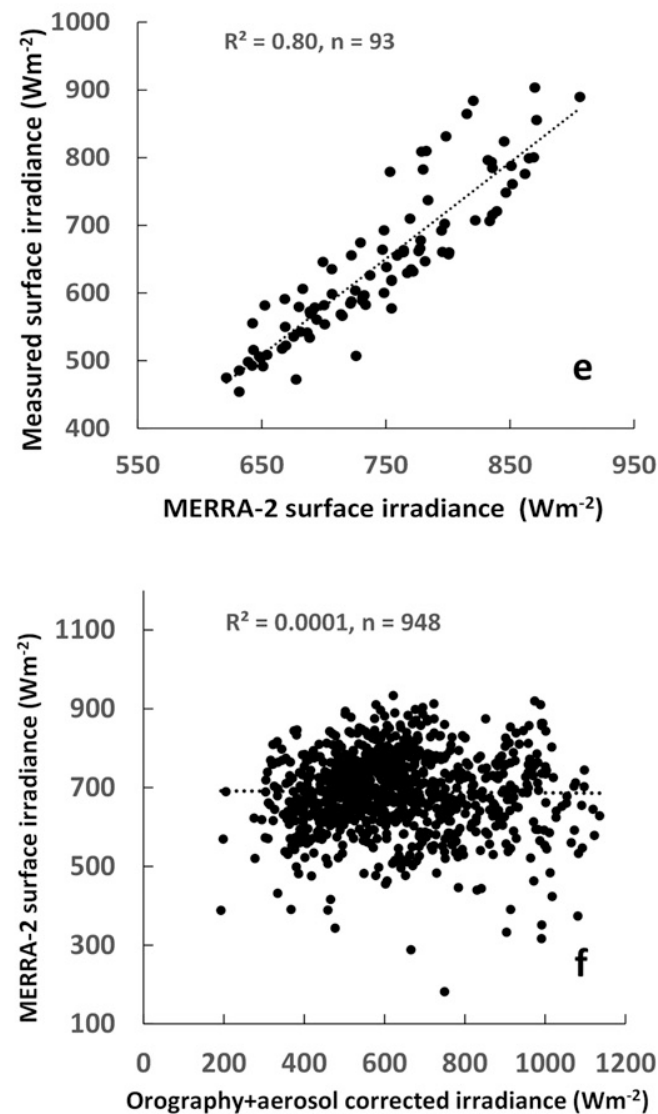

FIG. 5. Validation of estimated surface solar irradiance with ground-measured and MERRA-2 data: (a) basic vs measured data, (b) orography-corrected vs measured data, (c) orography + aerosol-corrected vs measured data, (d) orography + aerosol-corrected vs MERRA-2 data, (e) MERRA-2 vs measured data, and (f) orography + aerosol-corrected vs MERRA-2 data for hilly regions.

The overestimation is attributed mostly due to noninclusion of cloud and aerosol extinction and uncertainties in model parameters. It was expected to have a better correlation between terrain-corrected modeled irradiance and measured global horizontal irradiance but there was no significant improvement in surface flux at local incidence angle. The possible reasons could be nonavailability of ground radiation stations in the hilly regions. All the radiation stations data used in the present study are located in the plains and does not explicitly represents all the PSDs. It would have been better to have radiation stations on the inclined surface 
to validate the orography-corrected surface irradiance. As the stations are located in the plain the error due to orography is negligible. However, when the aerosol transmission was considered there is considerable improvement in relationship $\left(R^{2}=0.84\right.$, significant at $1 \%$ level) and the RMSE reduced to $31 \mathrm{~W} \mathrm{~m}^{-2}$ (relative RMSE of 0.06), which is better than what has been reported earlier by Dedieu et al. (1987) and Dutta et al. (2015). Besides model efficiency improved considerably (0.77), which is close to 1 (most accurate). The CRM indicates the overall under- or overestimations. For perfect estimation, the value would be zero (Dutta et al. 2015). The average CRM value for both the cases is -0.29 . For further details about CRM and ME, Bandyopadhyay et al. (2008) may be consulted.

As the distribution of ground radiometers do not explicitly represent the spatial variability, MERRA-2 surface solar radiation flux data at a 1-min interval were obtained for the study period. The purpose was to investigate whether the data can be used as a proxy of the ground radiometers for validation of the present model in the hilly regions. Overall, a very high correlation $\left(R^{2}=0.80\right)$ was obtained between MERRA-2 and ground-measured radiation data (Fig. 5e) but RMSE was very high, on the order of $115 \mathrm{Wm}^{-2}$. Overestimation of solar irradiance by MERRA- 2 in the plain areas could be due to aerosol climatology data used in the reanalysis product. Further to know the effectiveness of MEERA2 data in the hilly terrain also, six locations from each of the hilly PSDs were selected, keeping in view legitimate representation of different aspect classes. A very poor correlation was observed between modeled irradiance from MODIS data and MERRA-2 data (Fig. 5f), with high RMSE values. It also appears that MERRA-2 data get saturated at higher values of surface irradiance especially over the hilly Himalayan regions. Hence it can be inferred that MERRA-2 data are not a good alternative of ground radiometric measurements in complex topography possibly due to coarse-resolution grid $(\sim 31 \mathrm{~km})$ and nonconsideration of orographic parameters.

\section{Conclusions}

In the present study clear-sky instantaneous solar irradiance was estimated over 15 physiographic regions of India for the month of January. The purpose of which was feasibility study in order to develop method for climatology generation over the Indian region at a high spatial resolution, which is valid for the mountainous regions also. Dewpoint temperature profiles were extracted from Moderate Resolution Imaging Spectroradiometer (MODIS) instrument onboard the
Aqua satellite and used as input to a simple parameterization of the surface solar irradiance. The effect of terrain slope and aspect on direct radiation was taken into account by modifying the parameterized incoming shortwave flux by introducing the local incidence angle. Further the impact of aerosol extinction was introduced by multiplying the slope-corrected flux by a transmission factor obtained from satellite-derived aerosol optical depth and Ångström exponent. The results of MODIS derived instantaneous solar irradiance was compared with limited ground-based radiation observation and MERRA-2 data. The MODIS instantaneous surface irradiance was able to capture the spatial variability due to the latitudinal difference and orography. Although a significant positive correlation was observed between topography-corrected modeled irradiance and groundmeasured data but the improvement was marginal and the RMSE was very high $\left(187 \mathrm{~W} \mathrm{~m}^{-2}\right)$. The high RMSE could be due to nonconsideration of the aerosol extinction and uncertainties in the model input parameters, among other reasons. When the aerosol extinction was applied on solar irradiance computed on local incidence angle, there was a significant improvement in the $R^{2}$ value $\left(R^{2}=0.84\right)$ and the RMSE reduced to $31 \mathrm{~W} \mathrm{~m}^{-2}$ (relative RMSE of 0.06 ). To investigate the effect of aspect direction on solar irradiance, six of the hilly physiographic subdivisions were selected and the aspect directions were grouped into four classes. A large variation in the instantaneous flux $\left(161 \mathrm{~W} \mathrm{~m}^{-2}\right.$ in 2008 and $135 \mathrm{~W} \mathrm{~m}^{-2}$ in 2014) was noticed among different aspect classes considering all the hilly subdivisions together. The variability was observed to be highest in the Eastern Himalayas $\left(327\right.$ and $256 \mathrm{~W} \mathrm{~m}^{-2}$ in 2008 and 2014, respectively) whereas the Eastern and Western Hills the values are less than $28 \mathrm{~W} \mathrm{~m}^{-2}$.

As a proxy to ground radiation measurement MERRA-2 data were used for intercomparison with measured radiometric data and MODIS irradiance data. Although a significant positive $R^{2}(0.80)$ was observed between MERRA-2 and measured radiation data, RMSE was very high $\left(115 \mathrm{~W} \mathrm{~m}^{-2}\right)$ with a mean bias error of $101 \mathrm{~W} \mathrm{~m}^{-2}$. The overestimation of surface irradiance by MERRA-2 could be due to aerosol climatology data used and coarse-ground-resolution grid. A very poor agreement was noticed between modeled irradiance from MODIS and MERRA-2 with high RMSE values. It also appears that MERRA-2 data get saturated at higher values of surface irradiance, especially over the hilly regions. Hence it can be inferred that MERRA-2 data are not a good alternative of ground radiometric measurements in complex topography possibly due to coarse-resolution grid $(\sim 31 \mathrm{~km})$ and nonconsideration of orographic parameters. 
From the above findings, it can be concluded that the present method is able to model the instantaneous surface solar irradiance at reasonably good accuracy; however, further validation over the mountainous regions is required with inclined pyranometers to measure the effectiveness of the present method over hilly regions. There is also a need for an integrated approach of incorporating snow albedo, scattering and absorption due to ozone, relief shadow, and sky view factors in the orography + aerosol-corrected irradiance.

The limitation of the present study is that the method addresses only the clear-sky instantaneous surface solar irradiance. In future research, for the all-sky condition, a cloud transmission factor will be introduced, which acts as a modifier of clear-sky modeled radiation. The surface shortwave incoming flux will be computed in two different steps for 1) clear-sky pixels and 2) cloudy pixels based upon the lookup table and satellite-derived cloud microphysical parameters. MODIS (Terra/Aqua) daily level 2 cloud microphysical products, namely, cloud optical depth (COD) will be used. Further effort will also be made to study the feasibility and accuracy of the parametric and lookup table methods for the retrieval of surface solar irradiance from satellite data.

Acknowledgments. The authors are thankful to the anonymous reviewers for critical review of the manuscript and providing extremely useful suggestions to improve the quality. We sincerely acknowledge LAADS DAAC (ladsweb.nascom.nasa.gov/data) web services for providing MODIS data products, Solar Radiation Data (sodapro.com/web-services/meteo-data/merra) for MERRA-2 data and National Institute of Solar Energy for providing solar radiation data of different stations of India. We also thank Dr. Brent Holben, Dr. S. N. Tripathi and Dr. H. C. Viswakarma and their staff for establishing, maintaining and web enabling the AOD data of Jaipur, Kanpur and Gandhi College sites that were used in this investigation.

\section{REFERENCES}

Ångström, A., 1964: The parameters of atmospheric turbidity. Tellus, 16, 64-75, https://doi.org/10.3402/tellusa.v16i1.8885.

Babu, S., and Coauthors, 2013: Trends in aerosol optical depth over Indian region: Potential causes and impact indicators. J. Geophys. Res. Atmos., 118, 11 794-11 806, https://doi.org/ 10.1002/2013JD020507.

Bandyopadhyay, A., A. Bhadra, N. Raghuwanshi, and R. Singh, 2008: Estimation of monthly solar radiation from measured air temperature extremes. Agric. For. Meteor., 148, 1707-1718, https://doi.org/10.1016/j.agrformet.2008.06.002.

Barnes, W., T. Pagano, and V. Salomonson, 1998: Prelaunch characteristics of the Moderate Resolution Imaging Spectroradiometer
(MODIS) on EOS-AM1. IEEE Trans. Geosci. Remote Sens., 36, 1088-1100, https://doi.org/10.1109/36.700993.

Becker, C., and J. Boyd, 1957: Solar radiation availability on surfaces in the United States as affected by season, orientation, latitude, altitude and cloudiness. Sol. Energy, 1, 13-21, https:// doi.org/10.1016/0038-092X(57)90050-6.

Bisht, G., V. Venturini, S. Islam, and L. Jiang, 2005: Estimation of the net radiation Using MODIS (Moderate Resolution Imaging Spectroradiometer) data for clear sky days. Remote Sens. Environ., 97, 52-67, https://doi.org/10.1016/ j.rse.2005.03.014.

Bojanowski, J. S., A. Vrieling, and A. K. Skidmore, 2014: A comparison of data sources for creating a long-term time series of daily gridded solar radiation for Europe. Sol. Energy, 99, 152171, https://doi.org/10.1016/j.solener.2013.11.007.

Coops, N., R. Waring, and J. Moncrieff, 2000: Estimating mean monthly incident solar radiation on horizontal and inclined slopes from mean monthly temperatures extremes. Int. J. Biometeor., 44, 204-211, https://doi.org/10.1007/s004840000073.

Dedieu, G., P. Y. Deschamps, and Y. H. Kerr, 1987: Satellite estimation of solar irradiance at the surface of Earth using a physical model applied to Meteosat data. J. Climate Appl. Meteor., 26, 79-87, https://doi.org/10.1175/1520-0450(1987) $026<0079$ :SEOSIA $>2.0$.CO;2.

Dutta, D., D. Mahalakshmi, M. Singh, P. Goyal, S. Paul, J. Sharma, and V. Dadhwal, 2015: Satellite-based estimation of instantaneous radiative fluxes over continental USA-A case study. J. Indian Soc. Remote Sens., 43, 841-849, https://doi.org/ 10.1007/s12524-015-0449-1.

Fridley, J., 2009: Downscaling climate over complex terrain: High fine scale $(1000 \mathrm{~m})$ spatial variation of near-ground temperatures in a montane forested landscape (Great Smoky Mountains). J. Appl. Meteor. Climatol., 48, 1033-1049, https:// doi.org/10.1175/2008JAMC2084.1.

Fu, P., and P. Rich, 2002: A geometric solar radiation model with applications in agriculture and forestry. Comput. Electron. Agric., 37, 25-35, https://doi.org/10.1016/S01681699(02)00115-1.

Gates, D. M., 1980: Biophysical Ecology. Springer-Verlag, 635 pp.

Gautam, R., and Coauthors, 2011: Accumulation of aerosols over the Indo-Gangetic Plains and southern slopes of the Himalayas: Distribution, properties and radiative effects during the 2009 pre-monsoon season. Atmos. Chem. Phys., 11, 12 841-12 863, https://doi.org/10.5194/acp-11-12841-2011.

Geiger, R., R. Aron, and P. Todhunter, 2009: The Climate near the Ground. 7th ed. Rowman and Littlefield, 642 pp.

Gelaro, R., and Coauthors, 2017: The Modern-Era Retrospective Analysis for Research and Applications, version 2 (MERRA-2). J. Climate, 30, 5419-5454, https://doi.org/10.1175/JCLI-D-160758.1.

Hall, D., J. Key, K. Case, G. Riggs, and D. Cavalieri, 2004: Sea ice surface temperature product from MODIS. IEEE Trans. Geosci. Remote Sens., 42, 1076-1087, https://doi.org/10.1109/ TGRS.2004.825587.

Hofierka, J., and T. Cebecauer, 2008: Spatially distributed assessment of solar resources for energy applications in Slovakia. Folia Geogr., 12, 97-114.

Iqbal, M., 1983: An Introduction to Solar Radiation. Vol. XVIII. Academic Press, 390 pp.

Jacobson, M., 1999: Fundamentals of Atmospheric Modeling. Cambridge University Press, 828 pp.

Kobayashi, K., and M. Salam, 2000: Comparing simulated and measured values using mean squared deviation and its 
components. Agron. J., 92, 345-352, https://doi.org/10.2134/ agronj2000.922345x.

Kumar, R., and Coauthors, 2014: Effects of dust aerosols on tropospheric chemistry during a typical pre-monsoon season dust storm in northern India. Atmos. Chem. Phys., 14, 6813-6834, https://doi.org/10.5194/acp-14-6813-2014.

Lee, W., K. Liou, and C. Wang, 2013: Impact of 3-D topography on surface radiation budget over the Tibetan Plateau. Theor. Appl. Climatol., 113, 95-103, https://doi.org/10.1007/ s00704-012-0767-y.

Loague, K., and R. Green, 1991: Statistical and graphical methods for evaluating solute transport models: Overview and application. J. Contam. Hydrol., 7, 51-73, https://doi.org/10.1016/ 0169-7722(91)90038-3.

Massie, S., O. Torres, and S. J. Smith, 2004: Total Ozone Mapping Spectrometer (TOMS) observations of increases in Asian aerosol in winter from 1979 to 2000. J. Geophys. Res., 109, D18211, https://doi.org/10.1029/2004JD004620.

McVicar, T., T. Van Niel, L. Li, M. Hutchinson, X. Mu, and Z. Liu, 2007: Spatially distributing monthly reference evapotranspiration and pan evaporation considering topographic influences. J. Hydrol., 338, 196-220, https://doi.org/10.1016/ j.jhydrol.2007.02.018.

Niemelä, S., P. Räisänen, and H. Savijärvi, 2001: Comparison of surface radiative flux parameterizations. Part II: Shortwave radiation. Atmos. Res., 58, 141-154, https://doi.org/10.1016/ S0169-8095(01)00085-0.

Oliphant, A., R. Spronken-Smith, A. Sturman, and I. Owens, 2003: Spatial variability of surface radiation fluxes in mountainous region. J. Appl. Meteor., 42, 113-128, https://doi.org/10.1175/ 1520-0450(2003)042<0113:SVOSRF $>2.0 . C O ; 2$.

Pellicciotti, F., T. Raschle, T. Huerlimann, M. Carenzo, and P. Burlando, 2011: Transmission of solar radiation through clouds on melting glaciers: A comparison of parameterizations and their impact on melt modelling. J. Glaciol., 57, 367-381, https://doi.org/10.3189/002214311796406013.

Prasad, A. K., R. P. Singh, and A. Singh, 2004: Variability of aerosol optical depth over Indian subcontinent using MODIS data. J. Indian Soc. Remote Sens., 32, 313-316, https://doi.org/ 10.1007/bf03030855.

$\_,-$_ and _ 2006: Seasonal climatology of aerosol optical depth over Indian subcontinent: Trend and departures in recent years. Int. J. Remote Sens., 27, 2323-2329, https://doi.org/ 10.1080/01431160500043665.

Ramachandran, S., and R. Cherian, 2008: Regional and seasonal variations in aerosol optical characteristics and their frequency distributions over India during 2001-2005. J. Geophys. Res., 113, D08207, https://doi.org/10.1029/2007JD008560.

_ - S. Kedia, and R. Srivastava, 2012: Aerosol optical depth trends over different regions of India. Atmos. Environ., 49, 338-347, https://doi.org/10.1016/j.atmosenv.2011.11.017.

Rogers, R., and M. Yau, 1989: A Short Course in Cloud Physics. 3rd ed. Pergamon Press, 293 pp.

Ruiz-Arias, J., D. Pozo-Vázquez, V. Lara-Fanego, F. SantosAlamillos, and J. Tovar-Pescador, 2011: A high-resolution topographic correction method for clear-sky solar irradiance derived with a numerical weather prediction model. J. Appl. Meteor. Climatol., 50, 2460-2472, https://doi.org/10.1175/ 2011JAMC2571.1.

Sengupta, M., and Coauthors, 2015: Best practices handbook for the collection and use of solar resource data for solar energy applications. NREL Tech. Rep., 225 pp., http://www.nrel.gov/ docs/fy15osti/63112.pdf.
Senkova, A. V., L. Rontu, and H. Savijarvi, 2007: Parameterization of orographic effects on surface radiation in HIRLAM. Tellus, 59A, 279-291, https://doi.org/10.1111/j.1600-0870.2007.00235.x.

Smith, M., R. Allen, and L. Pereira, 1996: Revised FAO methodology for crop water requirements. Proc. Int. Conf. on Evapotranspiration and Irrigation Scheduling, San Antonio, TX, American Society of Agricultural Engineers, 116-123.

Srivastava, R., 2017: Trends in aerosol optical properties over South Asia. Int. J. Climatol., 37, 371-380, https://doi.org/ 10.1002/joc. 4710 .

Steiner, A., D. Mermelstein, S. Cheng, T. Twine, and A. Oliphant, 2013: Observed impact of atmospheric aerosols on the surface energy budget. Earth Interact., 17, https://doi.org/10.1175/ 2013EI000523.1.

Sukhera, M. B., and M. A. R. Pasha, 1987: Solar radiation maps for Pakistan. Sol. Wind Technol., 4, 229-238, https://doi.org/ 10.1016/0741-983X(87)90053-1.

Tian, Y., R. Davies-Colley, P. Gong, and B. Thorrold, 2001: Estimating solar radiation on slopes of arbitrary aspect. Agric. For. Meteor., 109, 67-74, https://doi.org/10.1016/S01681923(01)00245-3.

Tovar, J., F. J. Olmo, and L. Alados-Arboledas, 1995: Localscale variability of solar radiation in a mountainous region. J. Appl. Meteor., 34, 2316-2322, https://doi.org/10.1175/ 1520-0450(1995)034<2316:LSVOSR >2.0.CO;2.

Tovar-Pescador, J., D. Pozo-Vazquez, J. Ruiz-Arias, J. Batlles, G. Lopez, and J. Bosch, 2006: On the use of the digital elevation model to estimate the solar radiation in areas of complex topography. Meteor. Appl., 13, 279-287, https://doi.org/ 10.1017/S1350482706002258.

Urraca, R., E. Martinez-de Pison, A. Sanz-Garcia, J. Antoanzas, and F. Antonanza-Torres, 2017a: Estimation methods for global solar radiation: Case study evaluation of different approaches in central Spain. Renewable Sustainable Energy Rev., 77, 1098-1113, https://doi.org/10.1016/j.rser.2016.11.222.

_ and Coauthors, 2017b: Extensive validation of CM SAF surface radiation products over Europe. Remote Sens. Environ., 199, 171-186, https://doi.org/10.1016/j.rse.2017.07.013.

Vyas, S. S., B. K. Bhattacharya, and R. Nigam, 2016: Assured solar energy hot-spots over Indian landmass detected through remote sensing observations from Geostationary Meteorological Satellite. Curr. Sci., 111, 836-842, https:// doi.org/10.18520/cs/v111/i5/836-842.

Willmott, C., 1982: Some comments on the evaluation of model performance. Bull. Amer. Meteor. Soc., 63, 1309-1313, https://doi.org/10.1175/1520-0477(1982)063<1309:SCOTEO> 2.0.CO;2.

Yang, K., T. Koike, and B. Ye, 2006: Improving estimation of hourly, daily, and monthly solar radiation by importing global data sets. Agric. For. Meteor., 137, 43-55, https://doi.org/ 10.1016/j.agrformet.2006.02.001.

You, Q., A. Sanchez-Lorenzo, M. Wild, D. Folini, K. Fraedrich, G. Ren, and K. Shichang, 2013: Decadal variation of surface solar radiation in the Tibetan Plateau from observations, reanalysis and model simulations. Climate Dyn., 40, 2073-2086, https://doi.org/10.1007/s00382-012-1383-3.

Zhao, L., X. Lee, and S. Liu, 2013: Correcting surface solar radiation of two data assimilation systems against FLUXNET observation in North America. J. Geophys. Res. Atmos., 118, 9552-9564, https://doi.org/10.1002/jgrd.50697.

Zillman, J. W., 1972: A Study of Some Aspects of the Radiation and Heat Budgets of the Southern Hemisphere Oceans. Meteorological Study, Vol. 26, Bureau of Meteorology, 562 pp. 